\title{
DEFENDING SPACEFLIGHT - THE ECHOES OF APOLlO
}

\author{
Robert J. Rovetto \\ New York, USA \\ ontologos@yahoo.com \\ University of Maryland Alumnus 2007 \\ rrovetto@terpalum.umd.edu \\ University at Buffalo Alumnus 2011 \\ rrovetto@buffalo.edu
}

\begin{abstract}
This paper defends, and emphasizes the importance of, spaceflight, broadly construed to include human and unmanned spaceflight, space science, exploration and development. Within this discourse, I provide counter-replies to remarks by physicist Dr. Steven Weinberg against my previous support of human spaceflight. In this defense of peaceful spaceflight I draw upon a variety of sources. Although a focus is human spaceflight, human and unmanned modes must not be treated as an either-or opposition. Rather, each has a critical role to play in moving humanity forward as a spacefaring species. In the course of this communication, I also stress NASA's (and other space agency's) perennial role as a science and technology-driver, and its function to provide a stable and unified platform for space programs.
\end{abstract}

Keywords. Spaceflight; human spaceflight; manned spaceflight; NASA; space policy; philosophy of space exploration

\section{INTRODUCTION}

This paper defends, and emphasizes the importance of, spaceflight, broadly construed to include human and unmanned spaceflight, space science, exploration and development. Within this discourse I provide counter-replies to remarks against human (manned) spaceflight in particular.

In [1], I presented some common reasons for human spaceflight. In [2], Dr. Steven Weinberg, Nobel Laureate in Physics, expresses why he finds those reasons unconvincing. In this paper, I argue that his responses are insufficient, and do not provide justifications for rejecting the pursuit of human spaceflight. Some of my points are intended to anticipate other anti-human spaceflight positions, and may not be suggestive of Dr.Weinberg's view. In this defense of the pursuit of peaceful and responsible spaceflight, I draw upon a variety of sources that demonstrate the benefits of human and unmanned spaceflight.

It is important to explicitly state that the unmanned-manned spaceflight distinction is not an either-or opposition. They are not mutually exclusive modes of spaceflight and should not be

treated as such. Each has a critical role to play in moving humanity forward as a spacefaring 
species. To argue against one or the other-at least in a sweeping, unqualified, or contextindependent sense-is misguided. I believe spaceflight in general, and human spaceflight in particular, has been and can continue to be a means to uplift humanity on an individual and collective basis. It must not be taken lightly, but should be pursued responsibly with (inter)national resolve and cooperation. It should not be pursue with profiteering in mind, but should have scientific knowledge, technological advancement and infrastructure development as goals.

In the course of this communication, I also stress NASA's perennial role as a science and technology-driver, and its function to provide a stable and unified platform for space programs. More generally, I stress the essential role of public or national space programs, and call for greater support for these engines of innovation. For NASA to successfully do what it does best, not only does proper leadership need to be in place, but one or more long-term visions for scientifically, technologically and socially fruitful spaceflight must be formed.

The paper is divided thusly: section 2 summarizes the positive spaceflight position, section 3 presents my counter-responses to Dr.Weinberg [2], section 4 offers a discussion, and section 5 ends with some concluding remarks. Section 3 is divided according to the rationales for human spaceflight discussed in [1] and [2]. Key phrases or passages are either in bold or italicized text.

\section{SPACEFLIGHT POSITION SUMMARY}

The pro-spaceflight position I take is a positive one in at least two senses. First, in a normative sense: (human) spaceflight should be pursued. It is has value-scientific, technological, moral and otherwise. Second, it is positive in the sense of production, development and responsibly proactive engagement. I summarize the general idea below. In what follows 'HSF' is short for 'human spaceflight'.

- A fundamental, overarching goal, drive, and obligation is to positively develop and uplift humanity. ${ }^{\mathrm{i}}$

- When wisely conducted, spaceflight-unmanned and manned — can be a means toward that overarching and ever-present goal. It is one manifestation of that ever present goal. It is also arguably sufficient for it, with some reasons being that both forms of spaceflight (but perhaps HSF in particular) requires/involves/affords/realizes/engenders:

(a) Achieving higher levels of...

(i) Pedagogical and educational progress

(improving the quality of teaching, education and access to education)

(ii) Scientific knowledge, and technological development

(iii) Infrastructure

...that ideally benefit all persons, increasing the quality and care of life

(b) Engaging novel environments and conditions

(c) Increased potential to solve problems in other domains of society

(d) International cooperation, as well as interdisciplinary collaboration and research

(e) Stimulating, appealing to, and strengthening the selfless and positive aspects of the human spirit, the human mind, and the human heart, e.g., the drive to do good; the desire to be part of something greater than oneself; awe, wonder, and the sublime; the joy that comes from discovery, collective accomplishments, teamwork, etc.

- These reasons for (human) spaceflight are partially summarized as: 
- Scientific knowledge and discovery; Exploration itself

○ Practical benefits: spinoffs, problem-solving

- Aspirational, philosophical, aesthetic, intangible and uplifting effects on the intellect, mind, spirit. This includes inspiring effects on current and future generations

Improving life for posterity, and

○ Survival, e.g., the fate of our sun and solar system; unknown astronomical threats, etc.

- In short, "Space exploration stimulates the creation of both tangible and intangible benefits for humanity."[3, p.5]

- $\quad$ Spaceflight should be responsibly and peacefully pursued for the above reasons, but also because it may very well be a natural step in the direction of positive human progression.

HSF is essential at least in the sense that it is necessary for humanity to survive in the long-term. This is under the assumption that we do not develop the technology capable of preventing (or changing) astronomical phenomena from leaving Earth uninhabitable. Given that assumption, it is a moral imperative or obligation.

In [4], Schwartz gives specific arguments in favor of a moral obligation for space exploration, including the survival rationale (from asteroids and solar evolution). Although he no longer flat-out endorses those arguments, they remain supportive of spaceflight. In his more recent paper [51], he is correct in that space science (as contrasted with space development in the sense he uses) is of paramount importance. This point, which he explicitly states, is one that I have implicitly assumed. That is, in my writing I have made two assumptions. First, that HSF will and must involve (indeed focus on) scientific investigation, at least in our early developmental stages of space exploration. Two, I have implicitly assumed that space development is primarily about technological innovation and producing the physical infrastructure that will allow humanity to safely and sustainably live beyond Earth. I have not had commercial, recreational, or profitoriented space activities in mind, partly because these are dependent on a secure scientific and engineering foundation. Thus HSF must be scientifically and technologically-focused.

Responsibly engaging in HSF, and the research and development to see it accomplished, is simultaneously one path toward the manifestation of the creative and productive powers of the human mind, and is the manifestation itself. In manifesting those powers for the good of all, we are attending to our natural moral imperative (e.g. as expressed by the first bullet point). In this process, we stand to better ourselves and increase the quality and care of life.

The potential to do so exists as an extension of the imaginative possibilities, and discoveries, the mind conceives and apprehends. History-before and after project Apollo-has shown that this potential is actualizable. "Possibilities for benefit creation multiply rapidly when the products of space exploration interact with the imagination and creativity present in other fields of endeavour.'[3, p.6]

I say responsibly/wisely because it should be obvious that we must (continue to) take the proper precautions, and ensure capability-development for safe spaceflight. Astronaut Chris Hadfield says it well: "We're going to do it [forming a permanent human presence in space] because it's a natural human progression",ii and "[...] we are trying to do it right and it takes time, it takes patience and it takes tenacity"[39]. As he says, we are not going to engage because it "titillates the nerve endings."

So if, in expressing anti-HSF views, Dr.Weinberg [2] is claiming that we do not have the capability to safely engage in HSF missions, then that claim is different from an anti-human 
spaceflight position. The former does not imply the latter. If the former is true, then quite obviously to be successful (as well as safe) in HSF we must develop the requisite capabilities for, among other things, long-term missions. In other words, the absence of capability at a given time is not a reason against HSF research and development, and should not be used as such. Even in circumstances where there are good reasons to postpone HSF activities, there are no good reasons for never pursuing it.

- We are to develop increasing (human) spaceflight capability and pursue it wisely with long-term peaceful visions for humanity at large.

In supporting peaceful and responsible spaceflight I have the elevation (uplifting) of humanity in mind. Spaceflight must (and does) help realize the desire to engage in worthwhile pursuits that expand our knowledge, experiences and creative powers in a constructive manner. This is toward the remediation of our terrestrial problems. It is also toward the peaceful growth of humanity on Earth and beyond. It is perfectly feasible to pursue HSF in addition to other essential pursuits, such as the prevention and curing of illness, the eradication of poverty, and the education of all persons. HSF and other future-oriented activities are at least a potential means to success in these other vital societal domains.

We cannot-we must not-rely on short-sighted and profit-oriented incentives in pursuing HSF. At these early stages of spaceflight we need the secure foundations of long-term, publically-, nationally- and internationally-dedicated missions where scientific and technological research and development are essential parts, and which will give us the capability for stable and safe space development. We need national or publically-funded space agencies whose goals are not profit, but knowledge, scientific inquiry, engineering, infrastructure development, educational outreach, and so on.

By contrast, the rejection of HSF (at least in a sweeping manner) is a self-imposed limitation. It is a negative stance from the outset in that it minimizes capability and infrastructure development. Taking a stance that, from the start, constrains our peaceful abilities (and objects of inspiration and wonder) - as opposed to a stance that encourages them-is a self-imposed restriction at best. It is self-defeating and harmful at worst. Proponents of anti-human spaceflight views must therefore take care that those views are not anti-human in some way. 


\section{COUNTER-RESPONSES IN FAVOR OF HUMAN SPACEFLIGHT}

Dr. Weinberg [2] seemingly aims to minimize or otherwise deflate HSF positions by showing that the reasons in favor of HSF are either reasons for unmanned spaceflight or not reasons for HSF at all. In this section, I address each of his responses as they appear in his article, demonstrating that they fail to justify the anti-HSF position.

\subsection{ON SCIENCE}

Dr. Weinberg points to examples of unmanned missions that have contributed to scientific discovery. Unmanned missions are unquestionably important and vital ${ }^{\mathrm{iii}}$, but that is not disputed. Providing unmanned examples demonstrates that other forms of spaceflight can provide scientific knowledge, but it does not in any way diminish existing or potential scientific benefits of manned missions. It also neglects the fact that not all knowledge can be acquired by unmanned means of exploration. The idea is for human beings, ourselves, to enter space, and to engage in scientific, exploratory and developmental processes that will elevate, benefit and protect humanity. "The ultimate goal of space exploration is human exploration and as such Human Spaceflight is the main component" [5]. The attempt to minimize the scientific benefits of human spaceflight falls short.

He says that the locations where unmanned telescopes are placed are currently inaccessible and that repair missions will "probably never be cost-effective". However, we cannot assume distant locations in space will never be cost-effective, because economies are in fact mutable. Needless to say, it would also be an unreasonable to hold that we should avoid advancing the state of the art to make them accessible. Very simply, inaccessibility in the present is no reason to neglect making it accessible in the future.

Dr. Weinberg's assertion that I can point only to one type of human scientific study (suggesting there are few) does not hold up. The presentation of a non-exhaustive list of examples neither implies that there are no others, nor that they cannot be offered. The scientific benefits of human space exploration have been discussed time and again by others far more knowledgeable and eloquent than myself, but I will nonetheless list some additional benefits, below.

The added assertion that "[...] the only possible importance of [research into microgravity effects of humans] is as an adjunct to a program of human space flight" [2, p.229] is a curious one. This research is obviously a central part of human space exploration. Its importance rests firmly in learning how people can safely travel through (and thrive in) space for extended periods. Without this knowledge we would be venturing recklessly. As such, it is a necessary precursor for long-duration missions, and part of the capability-development of manned missions. This research also expands our biological knowledge, which can spur novel discoveries that can be applied to solving biomedical problems. The European Space Agency 
(ESA) publication "Benefits of Human Spaceflight" states: "In the long-term, this physiological research will pave the way for humans to travel beyond Earth orbit and begin the exploration of other worlds." [6, p.22] In other words, scientific research conducted by persons in the space environment is a necessary condition for sustainable human presence in space. It is also an ethical necessity, a responsibility, if we are to safely venture beyond Earth.

Below is a list of citied scientific and technological benefits of HSF. Key phrases are in bold text. The reader may also wish to review the benefits as described by Julie Robinson, Chief Scientist of International Space Station (ISS) [ $\left.{ }^{\mathrm{i}}\right]$.

○ Cancer research $\left[{ }^{v}\right]$

$\circ \quad$ Osteoporosis research [6, p.27]

- The study of muscular atrophy in microgravity is important for understanding "[...] the deterioration in muscle performance caused by prolonged disuse and ageing" [6, p.29]

- Professor P.E. Di Prampero of the University of Udine in Italy has said of the techniques resulting from life science research in space flight that they are now "[...] utilised to prevent the decline of muscle power caused by old age, neuromuscular diseases or prolonged immobilisation." [6, p.21]

- Professor H.C. Gunga of Charite-Medicine Univesity of Berlin says "Systemic research on human cardiovascular physiology [...] under microgravity conditions has revealed several important results that have improved our overall understanding of the physiological and pathological mechanisms." [6, p.23]

- Paraphrasing Dr. G. Clement, Faculte de Medicine Rangeuil, France: research into "[...] the adaptive mechanisms of spatial orientation" in microgravity may contribute to research into balance disorders. [6, p.25]

- Micro RNA research. "The team's investigation will compare the cells in spaceflight with those on the ground to identify unknown functions of microRNA and the functions they regulate in our bodies. Comparison of the space and Earth-based data will improve scientific knowledge of the fundamental biological processes critical for maintaining normal cell function." [43][41]

- "[...] biotechnology experiments on the growth of cells, tissues and bacteria, with potential applications in medicine, agriculture and environmental management (e.g. biological air filters and biosensors)." [6, p.16]

- "Sam Scimemi, director of the Space Station division at NASA Headquarters, recently said, 'Using the [International] space station to investigate ways we can improve communication rates with spacecraft beyond low-Earth orbit is another example of how the orbital complex serves as a stepping stone to human deep-space exploration." " [42]

- Professor G. Morfill, director of the Max-Planck-Institute, has described plasma research on the ISS saying: "The experiments yielded so much new and unexpected science-sometimes it simply took my breath away. And there's more to come..." [6]

$\circ$ The microgravity environment affords "[...] manufacturing processes not possible on Earth's surface", an example being the production of alloys that cannot otherwise be produced in a gravitational field. [7, p.4]

$\circ$ Combustion science research toward the better management of fire hazards and disasters.

"The human presence in space is a key factor in enabling new technologies to be tested in microgravity, leading to advanced solutions that provide benefits for power generation, transportation, safety and standard of living."[6, p.57]

A critic of HSF cannot justifiably criticize any perceived lack of results, or limited return on investment, by focusing on HSF or the space agency in isolation from the wider socioeconomic and political context. This is critical to understand. That context-leadership, policy, resource and funding allocation, educational sophistication of the workforce, and world eventshas effects that need to be taken into account. Any of these contextual factors can detrimentally 
affect the success of a given project. The question of whether the ISS, for example, is being utilized properly, and whether funds are being allocated properly, is independent of, and does not detract from, the value of HSF itself. In short, it is not a case against HSF, but a call for improving the situational context.

Furthermore, by its very nature research takes time, and even failures provide invaluable knowledge. Consider this 2007 article that addressed Dr. Weinberg's anti-HSF remarks.

"It is not possible to predict all of the benefits that either the human space program or particle physics research will do for our country, but that does not mean that the searches are not worthy. It is important for us to pursue, and solve, the deepest questions of the universe, just as it is important for us to explore our solar system and eventually live beyond the confines of our home planet. Our descendants will thank us for both pursuits" [8]

We must leave room for the unknown discovery. A similar idea is expressed by the International Academy of Astronautics 2010 Human Spaceflight Study Group Report:

"The answers are not yet available but considering the limitless benefit offered by Human Spaceflight and the concrete benefit generated by the required enabling technologies developed, it is reasonable that nations invest in their future, knowing that any investment presents risk" [5, emphasis added]

"It is unrealistic to judge the ISS based on its short-term payoff; by that standard, virtually all basic research in the sciences would be judged a failure." [44]

We should therefore scrutinize claims that express impatience with the research and development process. At the same time, we should not be impatient with regard to pursuing HSF, i.e., we must not venture hastily.

Moving on to the next response again HSF, it is false that microgravity research "disappears" [2, p.229] as a justification if given any reason against HSF. Some critics, for example, erroneously use monetary expense to argue against HSF, but this purported reason cannot eliminate the value (broadly construed) of the particular research.

Monetary cost is not a determining reason against HSF. Using it as such is far too simplistic a stance. As Dr. Ian Crawford, says, "[...] it is really an argument for reform of the way NASA $^{1}$ s budget is allocated by the US Congress rather than for the abandonment of a human space flight capability." [9] This is an example of a contextual factor (mentioned above) that is falsely used as a reason against HSF. Dr. Crawford and others have also pointed out that financial arguments are insufficient because the national costs of spaceflight have, in reality, been marginal as compared with overall national expenditures [10]. Spaceflight is affordable. Dr. Neil Degrasse Tyson has also fervently expressed his views against the idea that the United States cannot afford to fund spaceflight. He has communicated worries that congressional decisions to cut NASA funding do not factor in the negative consequences of those decisions. Indeed. On these points, see $[11][12]^{\mathrm{vi}}$.

Excessive preoccupation with cost and purported inaccessibility is inherently stifling because it focuses on limitations as if they could not be remedied. That is, it focuses on the negative. It appears to express an unwillingness to improve the situation, and thus a disregard for the future. It thereby has a retrogressive affect in that it neither considers existing options for 
beneficial reform, nor future potential. If we think in this manner we have already failed by narrowing the space of what is possible. Only a future-directed attitude will do.

Finally, to assert that unmanned or robotic missions can perform experiments more reliably is no doubt true for some tasks, but as a general statement it exaggerates the current level of unmanned technology. Human presence provides real-time (re)actions to changing environments and problems that may arise therein. It provides a level of general flexibility and manual dexterity that unmanned technologies do not presently offer. This translates to accomplishing tasks in less time. The time-delay to manage (diagnose, troubleshoot etc.) remotely operated vehicles demonstrates the benefits of in situ human activity. In situ resource utilization is a necessary part of space development, and human presence makes it more efficient and effective.

Additionally, the firsthand experience acquired and communicated by astronauts is invaluable. The phenomenological aspect of human spaceflight, and the knowledge it brings, is not something that artificially intelligent robotic systems can provide. They may transmit (near) real-time video presentations, and virtual presence using robotic avatars may provide an approximate direct experience, but these are quite different (and detached) from actual human presence in which a person interacts with their environment in an unmediated fashion. In short, "fully autonomous robots are still far from being able to duplicate the cognitive performance of a human"[13, p.347]. They do not come close to the human intelligence, creativity, improvisation, imagination, and problem-solving, specifically. We need the dynamic interplay of human beings and their environments to gain a broader picture of the space environment. For a more detailed discussion on robotic and human exploration, see [14].

"True, we can learn something by observing the heavens from Earth, or near-Earth. But to really understand the cosmos, we need to get out of the house, cross the street, and begin to explore the neighborhood." [15, p.39]

"Although we can send spacecraft and robots out to explore space for us, space exploration is at its most satisfying when carried out directly by a human being." [16, p.121]

"Thus it is humans, not machines, who must finally go into space" [17]

Once again, unmanned and manned modes of spaceflight are not mutually exclusive and should not be presented as such. "Because science is at the foundation of space exploration, it is important that NASA continue its intertwined paths of human and robotic exploration of space."[18, p15] We can all accept that human space travel will be a vital necessity at some point. Given the current limitations of space situational awareness and our ability to defend Earth, that point may be at our doorstep sooner rather than later. It does not make sense to avoid gaining first-hand experience, knowledge and capabilities before that time. To do otherwise is to not only stunt our growth ${ }^{\text {vii }}$, but play dice with our Earthly fate.

\subsection{ON INTERNATIONAL COOPERATION}

C Robert J. Rovetto, 2013-2016. All rights reserved. 
Dr. Weinberg has cited scientific projects other than space exploration that involve international cooperation. It is undisputed that such projects, e.g., research into usable thermonuclear power, are both significant for human progress and involve a great cooperative aspect. However, this fact neither minimizes, nor invalidates, the cooperative achievements and potential of HSF missions.

Foreshadowing the inspirational benefit of HSF (section 3.4), it can be argued that some of these other projects are not as accessible to the non-specialist public. They may lack the conspicuously positive impact on the human spirit that manned space exploration has had ${ }^{\text {viii }}$, and will continue to have as greater space milestones are achieved. This is not to deny the positive impact of other scientific endeavors, but only to say that there are certain aspects of HSF that people can easily relate to and draw inspiration from.

HSF quite simply involves human beings. It involves a combination of technological sophistication, physical exploration, and a variety of human elements. It demonstrates the intellectual potential of persons, as well as the novel locations we can reach. Like the exploratory expeditions of ages past, HSF shows us the places we can go and a sample of the activities we can perform, leaving the rest to the creative powers of the imagination. It can instill (or create) a sense of connectedness and unity. HSF is arguably more relatable than, and not as abstract as, some other projects. ${ }^{\text {ix }}$

For many, HSF touches that universal part of the human spirit to do goods works, to be part of a shared purpose, and to know that we are efficient parts of a greater system. Paraphrasing astronaut May Jemison at experiencing the sight of Earth from orbit:

"The perspective that stuck with me is that I am as much a part of this universe as any speck of star dust. I have as much right to be here. It connected me with this greater universe. That perspective of belonging was what was important to me."[19]

Positive effects such as these can engender and restore cooperative tendencies and diffuse negative ones. Spaceflight can thereby afford "the rechanneling of the aggressive human energies" [20 p.126].

"Space exploration provides a natural focus for international co-operation. In trying to build a stable geopolitical environment on Earth, it must be desirable to increase the range and depth of international collaborative projects. Human space exploration is an ideal candidate for enhancing a sense of international solidarity as it is highly visible to the global public." [21, P.19, emphasis added]

"Participation by other countries would be advantageous not only from the perspective of encouraging global cooperation, but also in terms of creating opportunities for synergistic research, risk reduction, cost-sharing and technology interchange."[22, p.78, emphasis added]

Dr. Weinberg is obviously incorrect (and exaggerating) when he says "[t]he special feature of manned spaceflight [...] is cooperation for no good purpose" [2, p.229]. HSF offers an opportunity to help create a peaceful global community via cooperation and interdisciplinary collaboration. The nature (complexity, difficult, vastness, etc.) of the very space enterprise demands we peacefully cooperate. International cooperation is particularly vital at these nascent stages of space exploration where the obstacles to overcome are many, the unknowns are waiting

C Robert J. Rovetto, 2013-2016. All rights reserved. 
to be discovered, and the physical infrastructure is in need of advancement. The European Space Agency says it succinctly:

"Human space exploration will be more effective and beneficial if planned and conducted with international cooperation in mind from the beginning. Such efforts represent a transition from the competitive beginnings of human spaceflight to one of routine and comprehensive cooperation."'[23, p.9, emphasis added]

This transition signals growth for international relations, and increases the range of what can be accomplished, not only in the space sector, but in other areas of society and life.

\subsection{ON EXPLORATION}

To claim that the public is (or would be) paying for the "thrills" of the "tiny fraction of humanity" [2, p.230] that goes into space is exaggerated. It is doubtful that those who have worked on, or who are minimally familiar with, the design, development and execution process of a spaceflight mission will agree with him. Regardless of the argumentative value, I believe it safe to say that most of the people involved sincerely believe in the value of the endeavor, a value that is quite different from thrills. I, for one, would be immensely proud and motivated to work on a NASA spaceflight project, and there are others from all backgrounds who feel similarly.

That only a small amount of people can go into space in the foreseeable future is not support for critics of HSF. Just as scientific research takes time, so does acquiring the technical capabilities to safely and reliably make HSF widely accessible. To halt HSF on that basis is to make the situation worse by turning the small amount to no amount at all. Such a negative act would harm the nation by neglecting areas of research and development that other nations are rightly pursuing.

The effects would arguably be felt in other sectors of society. In reducing investment in spaceflight, one danger is that a society may be reducing (albeit indirectly) the educational level of its youth and potential workforce by removing an activity that requires a certain level of intellectual sophistication and know-how. As Neil Armstrong said:

"A substantial current and long range threat is, and will be, the downward trend in engineering degrees granted [...]. Equally disconcerting are the projections for reductions in individuals grounded in science, technology, engineering, and mathematics."[24]

Without the possibility for HSF, students have one less reason to study these fields, and one less worthwhile aspiration in life. Take higher education as an example: [3, p.9] indicates the number of PhDs in Math, Physical Sciences and Engineering increased relatively significantly during the Apollo program but decreased after the last Apollo mission.

What a shame for our children to learn that they can neither venture into space nor contribute to humanity's astronautical knowledgebase because the research and infrastructure required for doing so has been cut. Must we be forever content with peering through telescopes or can we take the next steps toward seeing for ourselves. What a shame to tell our grandchildren that they cannot go beyond the night sky to those distant points of light.

C) Robert J. Rovetto, 2013-2016. All rights reserved. 
As for Dr. Weinberg's statement that the public gets more of a thrill from knowledge acquired via robotic explorers, I reiterate previous points. Naturally, we relate more easily when human beings are engaged. We share in their accomplishments, in the heights that have been reached, in the challenges that have been overcome, in the risk of the voyage, and in the shared humanity. They are role-models for many. For those of us that have not yet ventured into space, we see through them what we and our progeny can achieve.

We must therefore be cognizant of the positive psychological impact spaceflight can have, and how it contributes to human development at individual and collective levels. Seeing others venture into uncharted celestial expanses, and then to chart them, triggers awe and wonder, but also joy. It can instill a driving force in the observer, acting as a call to participate, as it has for some who witnessed the Apollo Moon landings. It is a call worthy of being answered. In transitioning to the inspirational rationale for HSF, consider the words of Dr. Carl Sagan:

"Exploratory spaceflight [...] elevates the general level of intellectual inquiry. The idea that we've now understood something never grasped by anyone who ever lived beforethat exhilaration [...]-propagates through the society, bounces off walls, and comes back at us. It encourages us to address problems in other fields that have also never before been solved. It increases the general sense of optimism in the society. It gives currency to critical thinking of the sort urgently needed if we are to solve hitherto intractable social issues. It helps stimulate a new generation of scientists." [25, p.129, emphasis added]

\subsection{ON INSPIRATION}

Dr. Weinberg says that other physicists he has met did not enter the field because of excitement about HSF. Be that as it may, I am confident that not only are there physicists, but also engineers, pilots, technicians, administrators, policy makers, non-specialists, and students who have been inspired by HSF, who are more than interested to go to space themselves and see humanity peacefully thrive beyond Earth (myself included). If we look to university aerospace departments, non-profit space organizations, individuals dreaming of being astronauts, and the growing number of space agencies in the international community (not to mention past and present astronaut cores) we would have views quite different than those Dr. Weinberg expresses. I would direct the reader to [45][46][47].

Although no formal survey was conducted, given the anti-HSF stance, it is possible that the uninterested physicists Dr.Weinberg mentioned represent a biased sample (if not a case of cherry-picking). This would be an example of the logical fallacy of Hasty Generalization, i.e., basing a conclusion on a small sample. From their lack of interest, we cannot conclude that no others were inspired by HSF or that it should not be pursued. For instance, no one would say that lack of interest in medicine calls for the cessation of medical science.

"Most Americans [...] still have a very engaged reaction once they meet someone who has experienced spaceflight. Young individuals, in particular, remain fascinated by the possibility that they could one day travel to space, and that possibility appears to motivate them toward excellence in their education." [26, p.283, emphasis added] 
"With the loss of the Challenger and its crew of seven, we learned, to our surprise, how much these adventures into space, into the future, mean to us as a people." [27, P.82, emphasis added]

"[H]uman spaceflight remains anchored in american culture and resilient in meaning."[27, p88]

Dr. Weinberg's indirect statement that human spaceflight does not involve "real science" [2, p.230] is a curt way saying that either HSF does not involve scientific activity (which is false) and/or that the scientific experiments conducted to date on manned platforms are of little scientific value or that there are better experiments. I leave judgments of the latter two to others, but given the previously mentioned experiments, it seems clear that worthwhile science is being done. For further information see [28][29][30][31][32]. Very importantly, the data gathered by astronautical science and spaceflight exploration is of use to various disciplines: biology, medicine, meteorology, material sciences, etc. At the very least, the potential is there and we must ensure that the ISS and other manned platforms are not underutilized. Aside from being intentionally provocative, if his aim is to stimulate a rational and unbiased (re)examination of existing or future scientific experiments for HSF missions, then by all means, but the above are not reasons against HSF itself.

Moving on to the next remark, let us assume for the sake of argument that his analogy is correct, i.e., that human spaceflight is a "spectator sport" in the sense that the majority of people cannot directly participate. It does not follow that we should stop the sport all together. If it did imply this, then we would be left with very few, if any, sports, and certainly no Olympic games, not to mention a number of other professions only few are fortunate to enter. Why not work toward making more so-called spectators into skillful participants.

Now, if we examine the analogy closer we may identify an instance of the logical fallacy of False Analogy. That is, the proposed analogy may be inapplicable for the following reasons. Football is a game/sport, whereas spaceflight is far from it. The sport does not require the degree of scientific and engineering sophistication that spaceflight does. Moreover, the stakes (in any meaningful sense of the word) are higher in HSF. Finally, HSF has a potential for creative growth that a game - which is restricted to a set of arbitrary rules-arguably does not. This is not to disparage sporting events, but only to show that the ploys used to minimize HSF do not work. If this is correct, then the analogy is far too simplistic, and the similarities one would expect in an (argument by) analogy are not present. Dr. Weinberg's responses, then, are insufficient to refute support for HSF and its inspirational rationale.

$$
* * *
$$

Human presence, sustainable activity and infrastructure (e.g., colonies) in space demonstrates the realizable aspect of human potential that otherwise may not have been known to exist in the minds of individuals. We see what we are capable of. This is indubitably a source of inspiration. Like other pursuits, it elevates the mind, and uplifts the spirit. In the ideal case, inspirational effects in tandem with a proper social and educational systems lead to the growth of new thinkers. The capacity to progress nations and humanity as a whole has thereby been increased in the population. This should eventually yield scientific, technological, philosophical and social advancements, i.e., manifestations of that increased capacity. Part of this must include solutions to terrestrial problems (illness, poverty, etc.). I do not intend to hyperbolize, but spaceflight (in addition to other human activities) is a means to elevate persons to higher states of

(C) Robert J. Rovetto, 2013-2016. All rights reserved. 
purpose, ability, intellect, and sense of self. See [33] on the personal and positive psychological impact of humans in space can have.

"[...] More fundamentally, a sense of purpose and achievement is important for the wellbeing of any civilization, and space exploration may be one of the few such options open to us. That societies and individuals need something like this, even if most people can only participate vicariously, has been noted by several thinkers over the years. [21]

"Human exploration of space can engage the public in new ways, inspiring the next generation of scientists and engineers, and contributing to the development of the future workforce in science, technology, engineering and mathematics (STEM) [as well as the arts and humanities]. By viewing other planets as well as our own from deep space, exploration helps to shape human perceptions of our place in the universe."[22, p.33]

In a presentation Astronaut Chris Hadfield explains being inspired by the Apollo landings:

"[W]hy would we take that risk? Why would you do something that dangerous? In my case the answer is fairly straightforward. I was inspired as a youngster that this was what I wanted to do. I watched the first people walk on the moon and to me, it was just an obvious thing -- I want to somehow turn myself into that."

We must not underestimate inspiration, awe and wonder for they stimulate the imagination and often lead to discovery, knowledge, great works, passion and a sense of purpose.

\subsection{ON SPINOFFS}

Dr. Weinberg is correct in that other large-scale projects are likely to produce spinoffs, but this too does not justify denying ourselves HSF. It does not deflate the beneficial spinoffs from HSF. The novel environments and conditions of spaceflight present a great potential for novel discoveries that may otherwise be unattainable by restricting ourselves to terrestrial projects. Mr. A.G. Aubert, Secretary General Eurospace Paris, France has said:

"Innovation is, without any doubt, one of the main drivers of economic growth. What other domains can rival human spaceflight, where everything has to be invented, in terms of bringing new technologies, discoveries and inventions?" $[6, \mathrm{p} .63]^{\mathrm{xi}}$

We also read:

"By stimulating cutting-edge technology, European human spaceflight-related research has led to the creation of more than 40 small- and medium-sized companies and several thousand new jobs. The new, high tech SMEs [subject matter experts] agree that what they learn from their space projects in terms of scientific principles, methods and technical and managerial expertise is particularly important as a basis for their future, non-space developments" [6, p.64]

Dr.Weinberg is incorrect in saying that the goal of keeping people alive in space has no value on Earth. First, investigation into maintaining human beings in space falls, in part, within 
the scope of the life sciences. What we learn may therefore be applied to biological and medical science on Earth. Again, the novel environments, and what we learn from interacting and experimenting in them has the potential to spur new innovative ideas, discoveries and technologies.

Second, keeping ourselves and posterity alive in space is self-evidently of the utmost value; it is our survival but also our development. This provides a moral impetus to do just that, including the development of planetary defenses from natural hazards. What more, aside from beaming with pride and joy at the news that their son or daughter is the next space explorer, any parent would want the know-how and technology in place to ensure the thriving of their children in space. To state the obvious, this calls for continued ever-advancing research and development in astronautics and space sciences.

Both human and unmanned forms of spaceflight make demands on science and technology. As we have seen, HSF introduces additional demands that stand to benefit citizens of Earth and progress humanity for the long-run.

"Human spaceflight is a technologically intensive activity, and during its execution new technologies are derived that have benefit to other government and commercial users of space, and to products that touch Americans daily. Access to and development of space is critical to our national welfare, and a well-crafted human exploration program can help to develop competitive commercial industries and important national capabilities"[22, p.33, emphasis added]

\subsection{ON HUMAN SURVIVAL AND FLOURISHING}

Dr. Weinberg agrees with survival as a reason for HSF, but says it is "[...] a task for the distant future". From one standpoint, this is an alarming statement for at least two reasons. First, it communicates, in effect: just leave it to the next guy. The next guy, however, is our children and their children. If this idea is seen through to completion, it implies that we need not take steps to prepare (or otherwise help) our descendants to protect themselves. Where is the concern for posterity? Would this not express a disregard toward the future? It is one thing to allow a child to get a scrape so that they learn to look where they run, but it is quite another to allow future generations to take on the task of, say, planetary survival by neglecting the research and development of infrastructure and capabilities that will allow not just survival, but flourishing.

The second reason for consternation is this. The assertion seems to presuppose that nothing of consequence can occur between the present and the distant future when the life stages of our sun endanger the Earth. This is an example of the Normalcy Bias or the fallacy of wishful thinking. As such it is fallacious. More to the point, (a) near-Earth asteroids have passed, and will continue to pass, close to Earth; (b) our knowledge and tracking capabilities of near-Earth and deep-space objects, not to mention our abilities to defend against them, is limited; and (c) we cannot exclude the possibility of as yet unknown potentially life-threatening astronomical phenomena. Consider this statement: "Earth will experience a close call on Sunday, as an asteroid discovered only a few days ago is expected to safely pass very close by." [40] The point is that 
the current state of space situational awareness (SSA), and our ability to defend against hazards to our terrestrial home must be improved. We need to acquire and proliferate knowledge of astronomical processes and advance planetary defense capabilities. Given the global nature of the threats, a global effort is called for, and HSF is part of the effort.

The universe will not wait, so to speak, for us to be ready. As any astronomer knows, the Earth is not isolated, but is part of a wider dynamic system, which is itself part of wider systems. We do not know enough about the causal interplay of these astronomical entities to sit back for generations with a self-imposed diminished capacity for scientific and technological advancement.

"[W]e can be sure that without the global knowledge that requires space science we will simply have no choice to make. Our descendants will suffer for it; and eventually our species will disappear at the earliest cosmic inconvenience." [34, p.16]

"If there is not a constant drive to advance our current technologies, then there is a very real risk that we will in the future be unable to respond to planetary threats." [4, p.87]

Inaction in the present can mean no possible action in the future. Whatever the perceived odds may be, we must not wait for some astronomical and global catastrophe before acting. Other species do not have the ability to prevent their own extinction, but we do. Just as neglect and cost or corner-cutting in the manufacturing of products on Earth has led to the deaths of end users, so it can be in the space domain... but at a global scale.

Survival is not a task for the distant future. We have both a natural intellectual curiosity to study the universe and arguably an obligation to venture through it, harnessing its laws to ensure our future survival and flourishing. We must act rationally and productively in the present to build a better future for ourselves and posterity. The Founding Fathers of the United States, the European intellectual tradition from which they originated, and many others in the history of thought, would not dare say that a task of great importance that is at least partially addressable in the present is best left as a burden for our children to bear tomorrow. They would not allow what could be done today to be done tomorrow and certainly not eons from now.

Developing a permanently space-faring humanity will not occur overnight, but progressively over time. There is no reason to avoid taking steps now, some of which include research into self-sustaining colonies. Dr.Weinberg appears to agree, as evidenced by his acceptance of the survival rationale for HSF and his mention of using Antarctica for colony research. Perhaps this is indication that he is not diametrically opposed to HSF simpliciter.

This project concept, like that of moon bases, is shared by many, and is a prudent strategy. We should use available terrains (including the ISS) toward stable and self-sustaining structures on the moon, Mars and beyond. This in no way implies the abandoned of HSF, but rather directs attention to the requisite steps for safe and successful HSF: the acquisition and development of the knowledge and engineering capability necessary to see missions safely achieved, and to form permanent extra-terrestrial colonies. In addition to direct planetary defense $\mathrm{R} \& \mathrm{D}$, taking these steps will put us on track to protecting ourselves (and the Earth) from natural space-borne threats.

This ends my counter-replies to some anti-HSF remarks. I will conclude this section with further points about Moon colonies, followed by discussion.

C Robert J. Rovetto, 2013-2016. All rights reserved. 
It is worth communicating that statements to the effect that "We've been there already" (e.g., the moon) are short-sighted at best, and dangerous at worst. This is especially true when uttered by public officials/authorities ${ }^{x i i}$. The moon, like the ISS and terrestrial locales, is a lowhanging fruit, and we should grab it. With such a proximate and stable resource, it is an obvious platform for a proof-of-concept, training ground, and a stepping stone. Astronaut Neil Armstrong argued on more than one occasion for the moon as a step beyond low earth orbit, and there are legitimate scientific reasons and terrestrial applications for doing so [48]. Following in the footsteps of project Apollo, our exploratory progenitors, the moon is a natural next step.

Other nations will not stop at a single manned visit to the Moon (or Mars), and then exclaim that they've been there, done that. They will return and it will not be to sightsee: they will explore, perform scientific experiments, develop, and in the process forge lasting and peaceful cooperative relationships... and they are right to do so. "America cannot maintain a leadership position without human access to space."[24], and as Dr.Tyson says "[...] here in America I see our infrastructure collapsing and no one is dreaming about tomorrow."[37]. If it is true that no one is dreaming of tomorrow, then anti-HSF attitudes and actions will certainly not help.

\section{DISCUSSION}

Although decisions of formal committees cannot remove the intrinsic worth of spaceflight, those reviewing spaceflight programs have on more than one occasion concluded in favor of HSF. The National Research Council Committee on Human Spaceflight, for instance, published a report [35] on their findings regarding the United States Human Spaceflight Program. The report discusses HSF rationales consistent with those mentioned here (and elsewhere by others), dividing them into pragmatic and aspirational rationales. The former include: economic stimulation, national security, education and inspiration, and scientific discovery. The latter include: human survival, shared destiny and aspiration to explore. ${ }^{\text {xiii }}$ Likewise, a 2008 Massachusetts Institute of Technology report states that benefits include exploration, national pride, and international leadership and prestige [36, p.2]. We also have the 2005 (and more recent) publication "Benefits of Human Spaceflight" [6] from the ESA.

The committee rightly concluded that a combination of these rationales argues "[...] for a continuation of the nation's human spaceflight program" [49] ${ }^{\text {xiv }}$. This conclusion-one of combined benefits of human spaceflight - is similar to Professor Crawford's view that a holistic perspective of scientific and other factors [10, p.47] is necessary for HSF. The rationales of problem-solving, ensuring survival and human flourishing are more than sufficient to support (human) spaceflight, however.

Peaceful and responsible human spaceflight that seeks to advance our knowledge, technology and infrastructure is inherently life-affirming. There is nothing about HSF itself that would call for its cutback or elimination. Anti-HSF proponents are misguided if they claim there is something wrong with it in principle. Yet HSF is often questioned because of monetary or political factors (or agendas), ignorance, or shortsighted gain of some kind. These considerations, however, do not reflect negatively on the activity of human spaceflight itself. Instead, flaws

C Robert J. Rovetto, 2013-2016. All rights reserved. 
should be found in the economic, political, and broader social contexts that negatively impact the development and success of beneficial HSF programs. Barring some extraordinary conditions ${ }^{\mathrm{xv}}$, were it not for political, financial, or otherwise some disruptive factors, I suspect that any rational and thoughtful person would support HSF (and spaceflight in general). Vis-à-vis the survival rationale we read: "[...]most reasonable people would then find it as a strong justification for the exploration and colonization of outer space"[34].

"All space-faring states agree on the need and desirability of maintaining human space activity in LEO [Low Earth Orbit] and of extending human missions to go beyond LEO (e.g., the Moon, Near Earth Objects), in coordination with robotic precursor missions." $[23$, P.53]

Support for the inspirational benefit of spaceflight, consider the testimony of Neil A. Armstrong before the Committee of Science and Technology at the United States House of Representatives:

"If one of the goals of government is to motivate its citizenry to 'be the best that they can be', few government agencies will surpass NASA in that function. I have met countless now middle aged adults who credit NASA's human space programs for inspiring them to study hard in order to master and excel in their chosen field." [24]

$\mathrm{He}$ is absolutely right on a number of fronts. NASA's role is not merely as an engine for science and technology, but also for inspiration. Moreover, it is (or should be) a rock-a point of stability - for proactive, cooperative, peaceful, and responsible public dedication to spaceflight. In short, public space agencies have at least two functions: one science and technology development, and two, serving as a symbol for dedication to peaceful spaceflight.

Unlike commercial or private sector companies that can come and go, institutions, such as the ESA and NASA, can and should persist in remaining science and technology-drivers, as well as engines of inspiration for all persons. Unlike the former, whose persistence may largely, if not entirely, depend on profitability, public space agencies do not have this dependency. The constancy of a nationally-dedicated space agency arguably mirrors the intangible benefits and aspirations of peoples. They must be centers for higher purposes.

Dr. Tyson expresses legitimate concerns about the progress of both NASA and the United States when he says:

"The National Aeronautics and Space Act of 1958 makes NASA responsible for advancing the space frontier. [...] we need something to keep the flame fanned. And that's the effect of NASA on who and what we are as a nation" [37]

We need leadership that will support that responsibility. Space policy professional John Logsdon says: "[...] we need JFK-like leadership to be equally clear in purpose and equally convincing in arguing for moving to a new era in U.S. human spaceflight"[50]. Public space agencies in conjunction with proper (1) leadership, (2) public educational systems, and (3) one or more long-term and sustainable visions/missions for spaceflight (manned and unmanned) will, indeed, continue to fan the flames of inspiration and innovation. It will blaze new trails for citizens of the world to follow. 
The sense of responsibility attributed to an organization, and formally expressed in the 1958 Space Act, can be understood as (or based on) a sense of responsibility for persons. On this, consider the following description of the spaceflight experience.

“[...] a humbling feeling. It's a feeling that says you have a responsibility. It's not for yourself. $[\ldots]$ you're a piece of this total life [...] and you have to bring that back somehow. That becomes a rather special responsibility and it tells you something about your relationship with this thing we call life [and existence].” [20, P.12-13]

For those that feel this at intellectual, spiritual and/or emotional levels (levels which are in fact interrelated), HSF is an obvious if not self-evident path for the near-term future, and quite certainly for the long-term. It is recognition of our positive potential (and rightful role) as cocreators in the universe. In this sense it elevates the mind and heart.

Finally, in their 1985 report [38] the National Commission for Space developed a human space exploration and development program. In describing the Commission's principles of space exploration as analogous to those of the Declaration of Independence, White [20, p.129,131] says that the principles cited by the Commission are self-evident. For many of us, HSF and spaceflight in general are self-evident (or nearly so). Yet it seems we must remind ourselves of its significance in order to ensure that we have our sights on the stars, i.e., on positively developing the future for the benefit of all.

\section{CONCLUSION}

I have defended spaceflight, broadly construed to include human and manned space exploration, science and development, by (i) providing counter-responses to anti human spaceflight remarks, particularly by Dr. Steven Weinberg; (ii) stressed that each form of spaceflight - manned and unmanned-has critical roles to play, and (iii) emphasized the importance of national or publically-funded space agencies.

The Apollo program gave us more than a glimpse of our capabilities. It planted a seed that has been calling for water. For many of us, and undoubtedly for those who experienced the landmark events, that call echoes in our souls. Project Apollo instilled an enthusiasm, optimism and confidence about the future, spurring the question: what else are we capable of ${ }^{\mathrm{xvi}}$ We must also ask: Given that we know and what we are capable of, won't limiting spaceflight have the opposite effect in one form or another?

Assume for the moment that there is other spacefaring sentient life beyond Earth. Imagine these space explorers pass the Moon, and glimpse the artifacts of Apollo. Will they wonder and ask us why we have not returned, why we have not explored and grown beyond Earth? ...or will they simply pass on by.

Regardless of any national political or military motivations of project Apollomotivations that were likely not held by all individuals involved ${ }^{\text {xvii }}$, mind you-what endures and is common to any peaceful HSF endeavor is something else entirely. "Beyond all the political and economic rationales, spaceflight is a spiritual quest in the broadest sense, one promising a revitalization of humanity and a rebirth of hope"[17] What endures, and what is common is that which is fundamental to the heart of humanity: it is, in part, the striving to better ourselves and help one another via ideation, inquiry, creation, education, exploration, cooperation and 
discovery. We experience this intertwined with curiosity, awe and wonder. It ultimately culminates in joy (at the moment of discovery), and an experience of the sublime (at moments of reaching new heights) as we did with Apollo. These are the echoes of Apollo, and they call for us to hear them clearly.

\section{Acknowledgments}

I would like to thank Dr.Mathias Brocchausen (University of Arkansas for Medical Sciences), Dr.Gonzalo Munevar (Laurence Technology University), and Dr.James Schwartz (Witchita State University) for their helpful comments on an earlier draft. 


\section{References}

[1] Rovetto, R. J. The Essential Role of Human Spaceflight. Space Policy 2013; 29(4):225-228. DOI:10.1016/j.spacepol.2013.08.001

[2] Weinberg, S. Response: Against manned space flight programs. Space Policy 2013; 29(4): 229-230. DOI:10.1016/j.spacepol.2013.10.005

[3] Benefits Stemming from Space Exploration. International Space Exploration Coordination Group, September 2013.

URL: http://www.nasa.gov/sites/default/files/files/Benefits-Stemming-from-Space-Exploration2013-TAGGED.pdf (Accessed Jan 24 2015)

[4] Schwartz, James S. J. Our Moral Obligation to Support Space Exploration. Environmental Ethics 2011; 33(1): 67-88. DOI: 10.5840/enviroethics20113317

[5] Human Spaceflight Study Group Report - November 17 2010. International Academy of Astronautics, United Nations, Committee on the Peaceful Uses of Outer Space. Presentation at CPUOS General Meeting, 54th Session Vienna. 1-10 June 2011.

URL: http://www.oosa.unvienna.org/pdf/pres/copuos2011/tech-13.pdf (Accessed Jan 24 2015)

[6] Bond, P., and The Directorate of Human Spaceflight. The Benefits of Human Spaceflight. European Space Agency 2005. URL: http://www.esa.int/esapub/br/br230/br230.pdf (Accessed Jan 24 2015). ISSN 0250-1589

[7] Sellars, J. J., Astore, W., Giffen, R., Larson, W. Understanding Space: An Introduction to Astronautics. $3^{\text {rd }}$ ed. McGraw-Hill; 2007.

[8] Prechtl, R., Whitesides, G. Commentary: The Value of Human Spaceflight. Space.com September 28, 2007.

URL: http://www.space.com/4187-commentary-human-spaceflight.html (Accessed Jan 24 2015)

[9] Crawford, Ian A. The Scientific Case for Human Spaceflight. Astronomy \& Geophysics; 1998; 39(6):pp.14-17, URL:

http://www.homepages.ucl.ac.uk/ ucfbiac/Space\%20Interests_files/A\&G\%20Spaceflight\%20Pap er.htm (Accessed Jan 24 2015)

[10] Crawford, Ian A. Towards and Integrated Scientific and Social Case for Human Space Exploration. Earth, Moon, and Planets 2005; 94(3-4): 245-266, Springer 2005

$\mathrm{URL}=\underline{\mathrm{http}} / / / \mathrm{www} \cdot$ homepages.ucl.ac.uk/ ucfbiac/Space\%20Interests files/EMP HSF paper.pdf

DOI 10.1007/s11038-005-9005-2

(C) Robert J. Rovetto, 2013-2016. All rights reserved. 
[11] Crawford, Ian A. The Scientific Case for a Human Spaceflight Infrastructure. Earth, Moon, and Planets 1999; 87(3): 221-231. DOI: 10.1023/A:1013199126659 URL:

http://www.homepages.ucl.ac.uk/ ucfbiac/EMP_infrastructure_paper.pdf (Accessed Jan 24 2015)

[12] DeGrasse Tyson, N. Testimony to the US Senate Committee on Commerce Science \& Transportation, March 7, 2012. New York City.

URL: http://www.commerce.senate.gov/public/?a=Files.Serve\&File_id=a602152c-2050-4e4ebdca-c02b0229d0e9 (Accessed Jan 24 2015)

[13] Lester, D. Achieving Human Presence in Space Exploration. Presence 2013; 22(4): 345-349. DOI:10.1162/PRES_a_00160

[14] Crawford, Ian A. Dispelling the myth of robotic efficiency: why human space exploration will tell us more about the Solar System than will robotic exploration alone. Astronomy and Geophysics 2012; 53(2): 2.22-2.26. DOI: 10.1111/j.1468-4004.2012.53222.x

[15] Dator, J.A. Social Foundations of human Space Exploration, Chapter 4:Culture and Space policies. Springer; 2012.

[16] Norberg, C. Human Spaceflight and Exploration, Chapter 4: Space exploration. Heidelberg: Springer; 2013.

[17] Aldrin, B.; Wachhorst, W. The Urge to Explore. Mechanical Engineering, 2004; 126(11): 37-38.

[18] Aerospace Industries Association. The role of space in addressing America's national priorities - A Special Report January 2009.

URL: http://www.nasa.gov/pdf/376452main_008\%20-

\%2020090714.3.AIA\%20report_space_0109.pdf (Accessed: March 11, 2015)

[19] Makers: Women in Space. PBS.org. URL: http://www.pbs.org/makers/season-two/womenin-space/ (Accessed: March 11, 2015)

[20] White, F. The Overview Effect. $2^{\text {nd }}$ ed. Virginia: AIAA; 1998.

[21] Crawford, I. A. To Still Boldy Go. Prospect March 2003; 84: 18-19.

$\mathrm{URL}=$ http://www.homepages.ucl.ac.uk/ ucfbiac/Space\%20Interests files/prospect.pdf Also on p.257 of [10]

[22] Review of US human spaceflight plans committee. Seeking a human spaceflight program worthy of a great nation. Washington DC: October 2009.

URL: http://www.nasa.gov/pdf/617036main_396093main_HSF_Cmte_FinalReport.pdf , http://www.nasa.gov/pdf/396093main_HSF_Cmte_FinalReport.pdf (Accessed March 11, 2015)

[23] Pace, S. Reibaldi, G. (Eds.) Future Human Spaceflight: The Need for International Cooperation. Human Spaceflight Study Group, International Academy of Astronautics Study Group: 2010. URL: http://iaaweb.org/iaa/Summit/IAA_Study-Human_Spaceflight.pdf (Accessed: March 11, 2015)

(C) Robert J. Rovetto, 2013-2016. All rights reserved. 
[24] Armstrong, N. Written Testimony of Neil A. Armstrong Before the Committee of Commerce, Science, and Technology United States House of Representatives. September 22,

2011.

URL:

http://democrats.science.house.gov/sites/democrats.science.house.gov/files/documents/Armstrong \%20Testimony\%202011-2\%20.pdf (Accessed: March 11, 2015)

[25] Sagan, C. Pale Blue Dot: A Vision of the Human Future in Space. 1997.

[26] Logsdon, J M. Fifty Years of U.S. Spaceflight: Why Is There Still a Controversy? in Dick, Steven J. NASA's First Fifty Years: Historical Perspectives, NASA SP2010-4704, Washington, Government Printing Office: 2010.

[27] Neal, V. Chapter 5: Framing the Meanings of Spaceflight in the Shuttle Era in Dick, S.J. Launius, R.D. (Eds.) Societal Impact of Spaceflight. National Aeronautics and Space

Administration, Office of External Relations, History Division. Washington, DC: 2007.

[28] European Space Agency. International Space Station - Benefits for Humanity. International Space Station Plays Role in Vaccine Development. Last update: Aug 162012.

URL:

http://www.esa.int/Our Activities/Human_Spaceflight/International Space Station Benefits for Humanity/International Space Station Plays Role in Vaccine Development (Accessed: March 11, 2015)

[29] National Aeronautics and Space Administration. International Space Station - ISS Benefits for Humanity. Rainey, K (Ed.). URL: http://www.nasa.gov/stationbenefits/ (Accessed: March 11, 2015)

[30] National Aeronautics and Space Administration. Space Station's Benefits for Humanity in Plain Sight in New Video Feature, Nov 25, 2013. Rainey, K (Ed.). Page Last Update: May 23 2014. URL: http://www.nasa.gov/mission_pages/station/research/news/benefits_video/\#.UvzKvaMUaE

[31] Canadian Space Agency. International Space Station Benefits for Humanity.

URL: http://www.asc-csa.gc.ca/eng/iss/benefits.asp

[32] Russian Space Agency. ISS Benefits for Humanity.

URL: http://knts.tsniimash.ru/en/site/Benefits.aspx

[33] National Aeronautics and Space Administration. Benefits for Humanity: Station Inspiration. November 18 2013. Wright, J. (Ed.) Last updated: February 252014.

URL: http://www.nasa.gov/content/benefits-for-humanity-station-inspiration

[34] Munevar, G. Space Exploration and Human Survival. Space Policy Space Policy 2014; 30(4):197-201.

C Robert J. Rovetto, 2013-2016. All rights reserved. 
[35] Daniels, M.E. Jr.; Lunine, J.I. Pathways to Exploration: Rationales and Approaches for a U.S. Program of Human Space Exploration. Committee on Human Spaceflight 2014. Power Point Presentation.

URL: http://sites.nationalacademies.org/DEPS/ASEB/DEPS 069080, http://www.nap.edu/catalog.php?record_id=18801

[36] Space, Policy, and Society Research Group. The Future of Human Space Flight. Massachusetts Institute of Technology: December 2008.

URL: http://web.mit.edu/mitsps/MITFutureofHumanSpaceflight.pdf

[37] DeGrasse Tyson, N. What NASA Means to America's Future. January 23, 2014.

URL: http://billmoyers.com/2014/01/23/what-nasa-means-to-america\%E2\%80\%99s-future/

(Accessed: March 11, 2015)

[38] Pioneering the Space Frontier: An Exciting Vision of Our Next Fifty Years in Space. The Report of the National Commission on Space.

URL: http://history.nasa.gov/painerep/begin.html, http://www.nasa.gov/pdf/383341main_60\%20\%2020090814.5.The\%20Report\%20of\%20the\%20National\%20Commission\%20on\%20Space.pd f (Accessed: March 11, 2015)

[39] Hadfield, C. Quotes in "Chris Hadfield says NASA's job is not to 'titillate'" by Pallab Ghosh. BBC News: May 122013.

URL: http://www.bbc.com/news/science-environment-22483934 (Accessed: March 11, 2015)

[40] Fritz, A. Newly discovered asteroid will narrowly miss Earth on Sunday. The Washington Post (Online). September 4 2014. URL: http://www.washingtonpost.com/blogs/capital-weathergang/wp/2014/09/04/newly-discovered-asteroid-will-narrowly-miss-earth-on-sunday/ (Accessed: March 11, 2015)

[41] National Aeronautics and Space Administration. MicroRNA Expression Profiles in Cultured Human Fibroblasts in Space. Last updated: January 28, 2015.

URL: http://www.nasa.gov/mission_pages/station/research/experiments/874.html (Accessed: March 11, 2015)

[42] National Aeronautics and Space Administration. NASA Beams "Hello, World!" Video from Space via Laser. Last updated: June 6th, 2014.

URL: http://www.nasa.gov/press/2014/june/nasa-beams-hello-world-video-from-space-via-laser/ (Accessed: March 11, 2015)

[43] Studying The Effects Of Microgravity And Radiation On Human Cells. Redorbit.com, February 28, 2014.

URL: http://www.redorbit.com/news/space/1113083978/microgravity-radiation-doublewhammy-human-cells-022814/ (Accessed: March 11, 2015)

[44] Bianco, W. “The International Space Station's scientific payoff is real. And increasing." The Washington Post Online. October 25, 2013.

URL: http://www.washingtonpost.com/blogs/monkey-cage/wp/2013/10/25/the-internationalspace-stations-scientific-payoff-is-real-and-increasing/ (Accessed: March 11, 2015)

C Robert J. Rovetto, 2013-2016. All rights reserved. 
[45] Crawford, I.A.; Dunkin, S.K., The Scientific Case for Human Spaceflight, Astronomy and Geophysics, 2001; 42:3.33-3.34.

URL:

http://www.homepages.ucl.ac.uk/ ucfbiac/Space\%20Interests_files/RAS_space_summary_2001. pdf (Accessed: March 11, 2015)

[46] Taranovich, S. "The top 10 reasons for the US to return to space exploration." EDN Network, August 09, 2013.

URL: http://www.edn.com/design/analog/4419551/The-top-10-reasons-for-the-US-to-return-tospace-exploration (Accessed: March 11, 2015)

[47] Ghosh, P. "Space travel vital to our survival, says UK astronaut.” BBC News (Online), January 242014.

URL: http://www.bbc.com/news/science-environment-25869272 (Accessed: March 11, 2015)

[48] Spudis, P.D., "Moon First-Mine the Asteroids Later." Airspacemag.com, August 6, 2014

URL: http://www.airspacemag.com/articles/moon-firstmine-asteroids-later-180952272

(Accessed: March 11, 2015)

[49] The National Academy of Sciences. Pathways to Exploration-Rationales and Approaches for a U.S. Program of Human Space Exploration. June 2014.

URL:

http://sites.nationalacademies.org/DEPS/cs/groups/depssite/documents/webpage/deps_088247.pd f (Accessed: March 11, 2015)

[50] Logsdon, J.M. “The End of the Apollo Era Finally?” Space News, June 30, 2010.

URL: http://spacenews.com/guest-blog-end-apollo-era-\%EF\%BF\%BD-finally/ (Accessed: March $11,2015)$

[51] Schwartz, J.S.J. 2014. Prioritizing scientific exploration: A comparison of the ethical justifications for space development and for space science. Space Policy, vol.30:no.4:pp 202-208.

\footnotetext{
i 'Positive development' and 'uplift' are not explicated here except to say that they are used in at least in the sense of doing good; increasing the human beings ability to do good, improve, realize their potential, contribute, cooperate, and
} 
so on. They have to do with touching that part of the human spirit that seeks to grow, have a positive effect, and do good. It may be helpful to remind ourselves of Article I of the United Nations outer space treaty of 1967, which states that space exploration is for the benefit (and province) of all. URL: http://history.nasa.gov/1967treaty.html, http://www.oosa.unvienna.org/oosa/SpaceLaw/outerspt.html

ii From a philosophical perspective, the concept of natural human progress raises questions, but I interpret these quotes as being consistent with the sort of positive direction and uplifting of humanity I have in mind. Natural human progression, is (or should be) an inclination, drive or natural directedness toward greater levels of good, positive development, and quality of life. It is toward generating conditions that better afford persons the ability and resources to realize their creative potential, and their potential to do good, e.g., solve problems, help others, etc. Aside from the common rationales, I believe spaceflight is an activity that moves in that direction if coupled with scientific and technological investigation and a sense discovery and exploration. Persons may not act in altruistic or beneficial ways, but I believe it is an inherent human drive, one that can become obscured by the many harmful socio-psychological influences that surround us from birth. These are by no means simple topics, but this will suffice for the present communication.

iii Unmanned exploratory vehicles, for instance, make spaceflight safer by: serving as scouts; providing situational awareness; performing survey missions, and thereby returning precious data that allows us to assess the environment for further exploratory potential, including manned missions. Photographic and video footage by unmanned systems display the beauty and mystery of the cosmos, stir the imagination, and offers (or triggers) new conceptions of the universe and our relation to it. This is to say nothing of communication satellites and other critical space assets.

${ }^{\text {iv }}$ http://www.nasa.gov/sites/default/files/files/Could-You-Choose-Just-One-2013-09.pdf

${ }^{v}$ http://blogs.nasa.gov/ISS_Science_Blog/2013/11/01/top-space-station-research-results-countdown-one-new-targetedmethod-of-chemotherapy-drug-delivery-clinical-breast-cancer-trials-now-in-development/

${ }^{v i}$ See also: http://www.youtube.com/watch?v=CbIZU8cQWXc , and http://www.penny4nasa.org/2012/08/09/we-stopped-dreaming-episode-2-a-new-perspective/

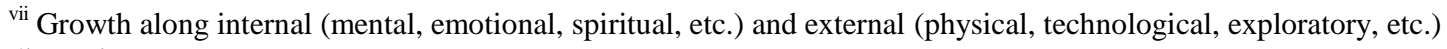
dimensions.

viii Compare the Apollo Moon landings and their positive influence on the psyche of many in the Apollo-era generation.

ix This partially depends on the quality and degree of public outreach, media attention, and the public educational level/system, among other factors.

${ }^{x}$ See this website for the video and transcript: http://www.ted.com/talks/chris hadfield what i learned from going blind in space

${ }^{x i}$ The reader may consult the NASA's Spinoff webpage (http://spinoff.nasa.gov/) and brochure for specific examples.

xii See: http://www.nasa.gov/news/media/trans/obama_ksc_trans.html. I was utterly flabbergasted upon hearing that statement, a combination of disbelief and frustration, as well as embarrassment for the nation.

xiii The latter can be understood as overlapping with the idea that space exploration is the natural progression of humanity.

${ }^{\text {xiv }}$ See also: http://www8.nationalacademies.org/onpinews/newsitem.aspx?RecordID=18801

${ }^{\mathrm{xv}}$ E.g., a pandemic or natural disaster, for example.

${ }^{x v i}$ Paraphrase astronomer Carl Sagan as heard in: http://www.youtube.com/watch?v=8Xtly-dpBeA\&index=8\&list=PLF17F07CFC3208E29

C Robert J. Rovetto, 2013-2016. All rights reserved. 
${ }^{x v i i}$ In all likelihood, many were motivated primarily by novel scientific and engineering pursuits, or by the pursuit of space exploration itself.

C Robert J. Rovetto, 2013-2016. All rights reserved. 